07

\title{
Особенности частотной зависимости вольт-фарадных характеристик полупроводниковой структуры фотоэлектрического преобразователя на основе $p-n$-перехода с антиотражающей пленкой пористого кремния
}

\author{
(C) В.В. Трегулов \\ Рязанский государственный университет им. С.А. Есенина, \\ 390000 Рязань, Россия \\ e-mail: trww@yandex.ru
}

(Поступило в Редакцию 23 фревраля 2018 г.)

\begin{abstract}
Проведены исследования частотной зависимости вольт-фарадных характеристик полупроводниковой структуры, содержащей антиотражающую пленку пористого кремния, сформированную электрохимическим травлением над $p-n$-переходом. Также исследованы спектры фотолюминесценции слоев пористого кремния экспериментальных образцов. Установлено, что характер вольт-фарадных характеристик определяется конкуренцией влияния емкости $p-n$-перехода и поверхностной структуры, возникающей в пленке пористого кремния вследствие неоднородности ее строения. Предложена модель строения слоев исследуемой полупроводниковой структуры и емкостная схема замещения.
\end{abstract}

DOI: 10.21883/JTF.2018.12.46789.83-18

\section{Введение}

Пленка пористого кремния (por-Si), применяемая в качестве антиотражающего покрытия, способствует существенному повышению эффективности кремниевого фотоэлектрического преобразователя на основе $p-n$-перехода [1]. Подобные полупроводниковые структуры актуальны для применения в солнечной энергетике и создания датчиков оптического излучения $[1,2]$. В настоящее время основное внимание уделяется исследованиям оптических характеристик (отражательная способность поверхности) и механизмов токопрохождения в указанных полупроводниковых структурах [1]. Изучению вольт-фарадных характеристик (ВФХ) уделяется меныше внимания. Вместе с тем изучение ВФХ актуально, так как позволяет уточнить модель строения слоев полупроводниковой структуры. В работе [3] представлено объяснение особенностей высокочастотной ВФХ полупроводниковой структуры с пленкой por-Si, сформированной над $p-n$-переходом.

Основной задачей настоящей работы является исследование особенностей частотной зависимости вольтфарадных характеристик обсуждаемой полупроводниковой структуры. Целью исследований является уточнение модели внутреннего строения слоев изучаемой полупроводниковой структуры.

\section{Описание образцов и методики исследования}

В качестве подложек использовались кремниевые монокристаллические пластины $p$-типа проводимости с удельным сопротивлением $1 \Omega \cdot \mathrm{cm}$ и ориентацией поверхности (100). Подложки подвергались жидкостному химическому травлению в водном растворе КОН. После травления формировался $n^{+}-p$-переход с глубиной залегания не более $0.5 \mu \mathrm{m}$ с помощью термической диффузии фосфора при температуре $1100^{\circ} \mathrm{C}$ в течение $10 \mathrm{~min}$. Пленка por-Si формировалась на поверхности $n^{+}$-слоя анодным электрохимическим травлением в гальваностатическом режиме при плотности тока $20 \mathrm{~mA} / \mathrm{cm}^{2}$. Использовался электролит, состоящий из смеси $\mathrm{HF}$ и $\mathrm{C}_{2} \mathrm{H}_{5} \mathrm{OH}$ (соотношение 1:1). Были изготовлены три образца - № 2, № 3 и № 4 при значениях длительности электрохимического травления 5, 10 и $30 \mathrm{~s}$ соответственно. Образец № 1 представляет собой полупроводниковую структуру с диффузионным $n^{+}-p$-переходом без пленки por-Si. Для проведения электрических измерений формировались серебряные контакты к пленке por-Si и кремниевой подложке $p$-типа (на противоположных поверхностях полупроводниковой структуры). Использовалась серебряная паста типа ФС1127 (ОАО „Монокристалл“, Россия), применяемая при изготовлении фронтальных контактов кремниевых фотоэлектрических преобразователей солнечного излучения. Образцы № 2-4 аналогичны полупроводниковым структурам, исследованным в работах [3-5].

Измерения ВФХ проводились с помощью цифрового измерителя иммитанса Е7-20 (МНИПИ, Белоруссия) при значениях частоты тестового сигнала 1,10 , $100 \mathrm{kHz}, 1 \mathrm{MHz}$. Спектры фотолюминесценции пленок por-Si измерялись спектрометром USB-4000-VIS-NIR (Ocean Optics, USA). Возбуждение фотолюминесценции осуществлялось полупроводниковым диодным лазером, работающим на длине волны $405 \mathrm{~nm}$, мощность излучения составляла $2 \mathrm{~mW}$. Все измерения проводились при температуре образцов $300 \mathrm{~K}$. 


\section{Результаты эксперимента}

Для образца № 1 измерение ВФХ проводилось на частоте измерительного сигнала $1 \mathrm{MHz}$, для образцов № 2-4 - на частотах $1,10,100 \mathrm{kHz}, 1 \mathrm{MHz}$. Измеренные ВФХ представлены на рис. 1-3 в виде зависимостей $(C / S)^{-2}=f(U)$, где $C-$ емкость образца, $S-$ его площадь, $U$ - постоянное напряжение обратного смещения. Для исследуемых образцов обратное смещение соответствует положительным значениям $U$, полярность определяется знаком напряжения на контакте к por-Si. Высокочастотные ВФХ (1 MHz) образца № 1 приводятся на рис. 1-3 с целью сравнения с ВФХ образцов № 2-4.

Спектры фотолюминесценции пленок por-Si образцов № 2-4 представлены на рис. 4.

\section{Обсуждение результатов эксперимента}

Линейность высокочастотной ВФХ (1 MHz) образца № 1, представленной на рис. 1-3, свидетельствует о том, что $p-n$-переход в исследуемых полупроводниковых структурах перед формированием пленки por-Si являлся резким. Вид высокочастотных ВФХ (1 MHz) образцов № 2-4 существенно отличается от образца № 1 (рис. 1-3). В работе [3] указанная особенность высокочастотных ВФХ изучаемых образцов была объяснена формированием поверхностной МДП-структуры на $n^{+}$-слое в ходе электрохимического травления. В качестве диэлектрического слоя выступает поверхностная область por-Si, содержащая наиболее мелкие кремниевые кристаллиты и включения окислов кремния $\mathrm{SiO}_{x}$. Полупроводниковый слой рассматриваемой МДП-структуры находится на поверхности более крупных кремниевых кристаллитов в пленке por-Si. При образовании

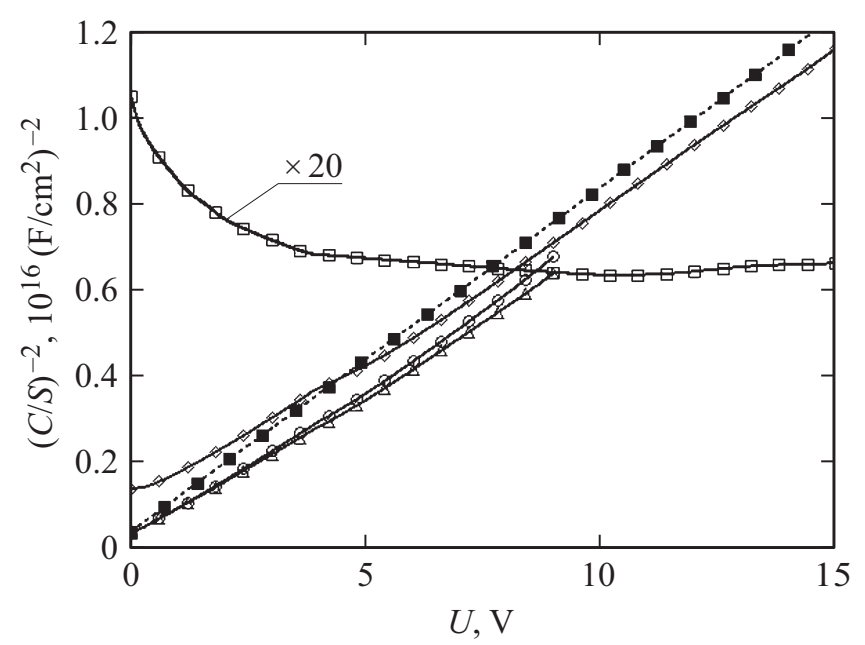

Рис. 1. ВФХ образцов № 1 и № 2 при разных частотах измерительного сигнала: - для образца № 1 при частоте $1 \mathrm{MHz}, \square-$ для образца № 2 при частоте $1 \mathrm{MHz}, \diamond-$ для образца № 2 при частоте $100 \mathrm{kHz}$, о - для образца № 2 при частоте $10 \mathrm{kHz}, \triangle$ - для образца № 2 при частоте $1 \mathrm{kHz}$.

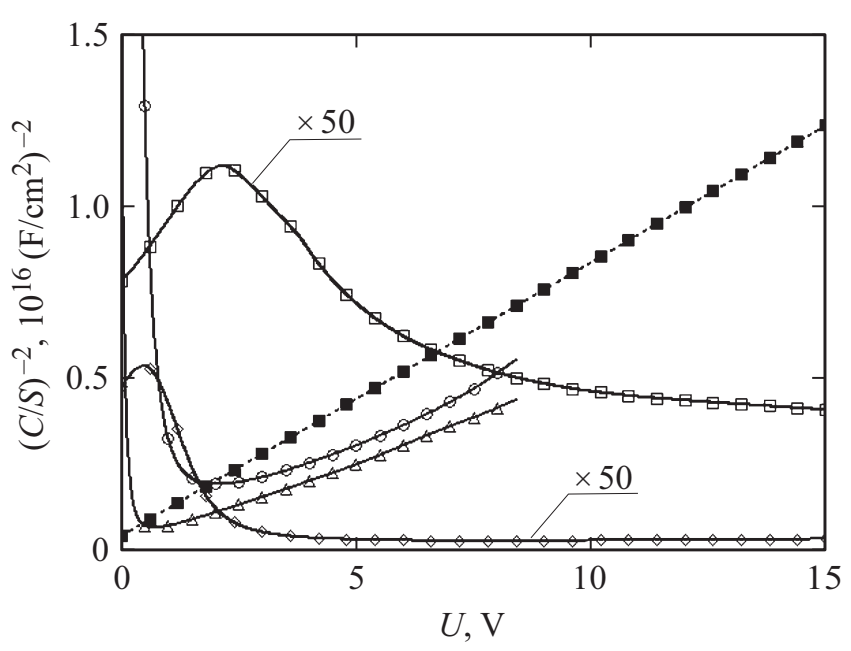

Рис. 2. ВФХ образцов № 1 и № 3 при разных частотах измерительного сигнала: $\mathbf{\square}$ - для образца № 1 при частоте $1 \mathrm{MHz}, \square-$ для образца № 3 при частоте $1 \mathrm{MHz}, \diamond-$ для образца № 3 при частоте $100 \mathrm{kHz}$, о - для образца № 3 при частоте $10 \mathrm{kHz}, \triangle$ - для образца № 3 при частоте $1 \mathrm{kHz}$.

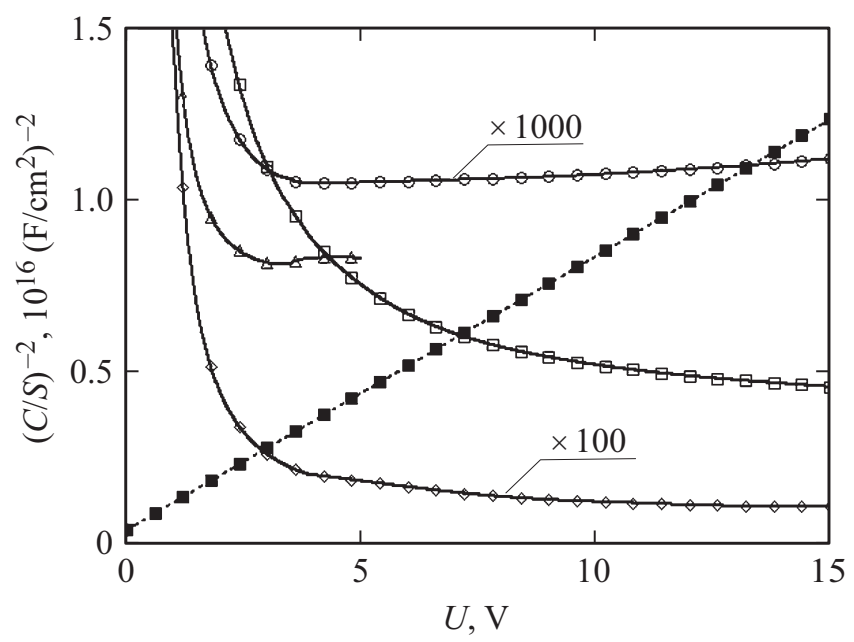

Рис. 3. ВФХ образцов № 1 и № 4 при разных частотах измерительного сигнала: - для образца № 1 при частоте $1 \mathrm{MHz}, \square$ - для образца № 4 при частоте $1 \mathrm{MHz}, \diamond-$ для образца № 4 при частоте $100 \mathrm{kHz}$, о - для образца № 4 при частоте $10 \mathrm{kHz}, \triangle$ - для образца № 4 при частоте $1 \mathrm{kHz}$.

por-Si может происходить электрическая пассивация примесных атомов исходной $n^{+}$-области кремния за счет внедрения водорода при электрохимическом травлении. В результате в полупроводниковом слое поверхностной МДП-структуры концентрация мелких доноров может быть меньше, чем в исходном $n^{+}$-кремнии.

На частоте $100 \mathrm{kHz}$ ВФХ образца № 2 (рис. 1) при значениях $U$ в диапазоне $0-5 \mathrm{~V}$ отклоняется от линейной зависимости, а при $U>5 \mathrm{~V}$ - близка к линейной. Это можно объяснить тем, что при $U>5 \mathrm{~V}$ вид ВФХ главным образом определяется влиянием барьерной емкости резкого $p-n$-перехода, а при $U<5 \mathrm{~V}$ 


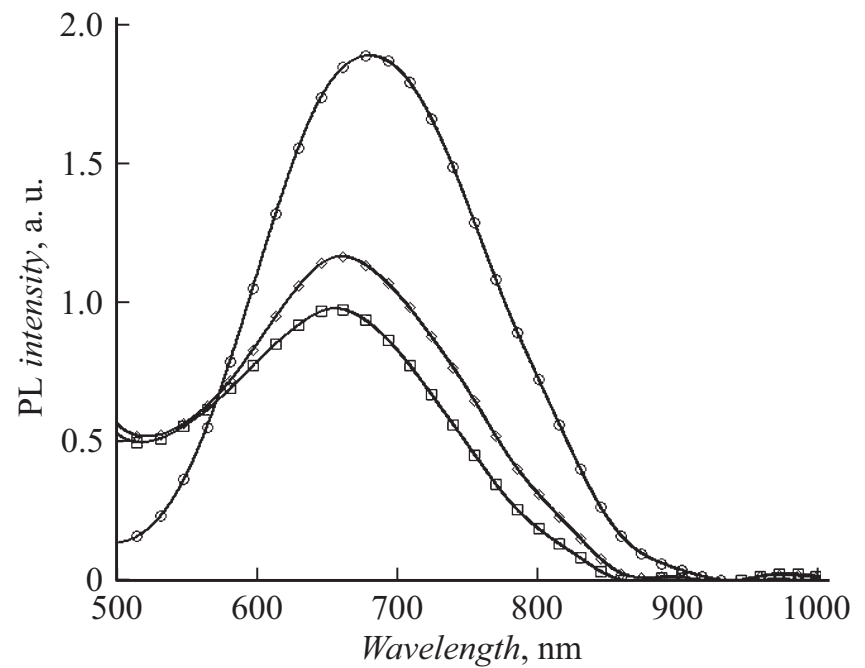

Рис. 4. Спектры фотолюминесценции образцов № 2 ( $\square$ ), № $3(\diamond)$, № 4 (०).

на ВФХ преобладающее влияние оказывает поверхностная МДП-структура. При частотах измерительного сигнала 1 и $10 \mathrm{kHz}$ ВФХ образца № 2 линейны (рис. 1). Следовательно, в указанных условиях ВФХ образца № 2, главным образом, определяются влиянием барьерной емкости резкого $p-n$-перехода.

Для образца № 3 (рис. 2) при частотах $1 \mathrm{MHz}, 100$ и $10 \mathrm{kHz}$ вид ВФХ существенно отличается от характерного для барьерной емкости резкого $p-n$-перехода. На частоте $1 \mathrm{kHz}$ ВФХ образца № 3 (рис. 2) при $U>2.5 \mathrm{~V}$ становится линейной, что может быть связано с преобладающим влиянием барьерной емкости резкого $p-n$-перехода.

Вид ВФХ образца № 4 для всех значений частоты измерительного сигнала (рис. 3) не характерен для барьерной емкости $p-n$-перехода. Это можно объяснить преобладанием влияния поверхностной МДП-структуры.

Наблюдаемый характер частотной зависимости ВФХ образцов № 2-4 во многом определяется особенностями структуры пленки por-Si. В ряде работ, например [6-8], отмечается, что пленка por-Si состоит из слоев с различающимися свойствами. Слои por-Si, находящиеся ближе к границе с монокристаллическим кремнием, образованы более крупными кремниевыми кристаллитами, не создающими эффективной фотолюминесценции в видимой области спектра. Слой por-Si, находящийся ближе к внешней поверхности, состоит из наиболее мелких кремниевых кристаллитов. Согласно [6-8], именно этот слой обеспечивает интенсивную фотолюминесценцию por-Si в видимом диапазоне.

Следует отметить, что в работах [6-8] исследовались образцы с достаточно толстыми пленками por$\mathrm{Si}$ (несколько микрометров). В работе [7] общая толщина пленки por-Si исследуемых образцов составляла $8-175 \mu \mathrm{m}$, при этом толщина приповерхностного слоя por-Si, содержащего наиболее мелкие кристалли- ты составляла 1-20 $\mu \mathrm{m}$. Толщина пленки por-Si образцов № 2-4, исследуемых в настоящей работе, сравнима с глубиной залегания $p-n$-перехода $(0.5 \mu \mathrm{m})$, что существенно меньше, чем в работах [6-8]. В связи с этим обстоятельством для уточнения структуры слоев пленки por-Si образцов № 2-4 измерялись спектры фотолюминесценции (рис. 4).

С ростом длительности процесса электрохимического травления наблюдается увеличение интенсивности фотолюминесценции, максимум спектра сдвигается в сторону более длинных волн (рис. 4). Рост интенсивности фотолюминесценции может быть объяснен увеличением толщины приповерхностного слоя пленки por-Si, содержащего наиболее мелкие кристаллиты. Заметное расширение спектральной линии для образца № 4 по сравнению с образцами № 2 и № 3 в сторону больших длин волн (рис. 4) с точки зрения квантово-размерной модели por-Si может означать увеличение количества более крупных кристаллитов [9]. Этим также можно объяснить сдвиг максимума спектра фотолюминесценции в сторону более длинных волн (рис. 4).

Таким образом, из анализа спектров на рис. 4 можно заключить, что в образцах № 2-4 с увеличением длительности процесса электрохимического травления возрастает толщина приповерхностного слоя пленки por$\mathrm{Si}$, содержащего наиболее мелкие кремниевые кристаллиты, отвечающие за фотолюминесценцию в видимой области спектра. Следовательно, увеличение длительности электрохимического травления должно приводить к снижению емкости приповерхностного слоя por-Si исследуемых образцов.

С точки зрения электрофизических процессов приповерхностный слой por-Si может обеспечивать туннельный механизм токопрохождения. Так, в работе [10] отмечалось, что туннелирование носителей заряда может происходить внутри пленки por-Si между энергетическими уровнями ловушек на поверхности кремниевых кристаллитов через барьеры $\mathrm{SiO}_{x}$. В работе [4] туннелирование носителей заряда наблюдалось в полупроводниковой структуре, аналогичной образцу № 2, которая исследовалась методом температурной зависимости вольтамперных характеристик.

На основе представленных результатов можно предложить модель строения слоев исследуемой полупроводниковой структуры в виде показанной на рис. 5. Представленная модель соответствует случаю, когда толщина пленки por-Si меньше глубины залегания $p-n$-перехода (образцы № 2 и № 3). Пленка por-Si состоит из приповерхностной области с наиболее мелкими кремниевыми кристаллитами (слой 1 на рис. 5) и внутренней области с более крупными кристаллитами (слой 2 на рис. 5). Исследование образцов, аналогичных № 2-4, методом токовой релаксационной спектроскопии глубоких уровней, проведенное в работе [5], показало, что даже при небольших длительностях процесса электрохимического травления (образцы № 2 и № 3) наблюдается трансформация дефектов с глубокими энергетическими уровнями. 


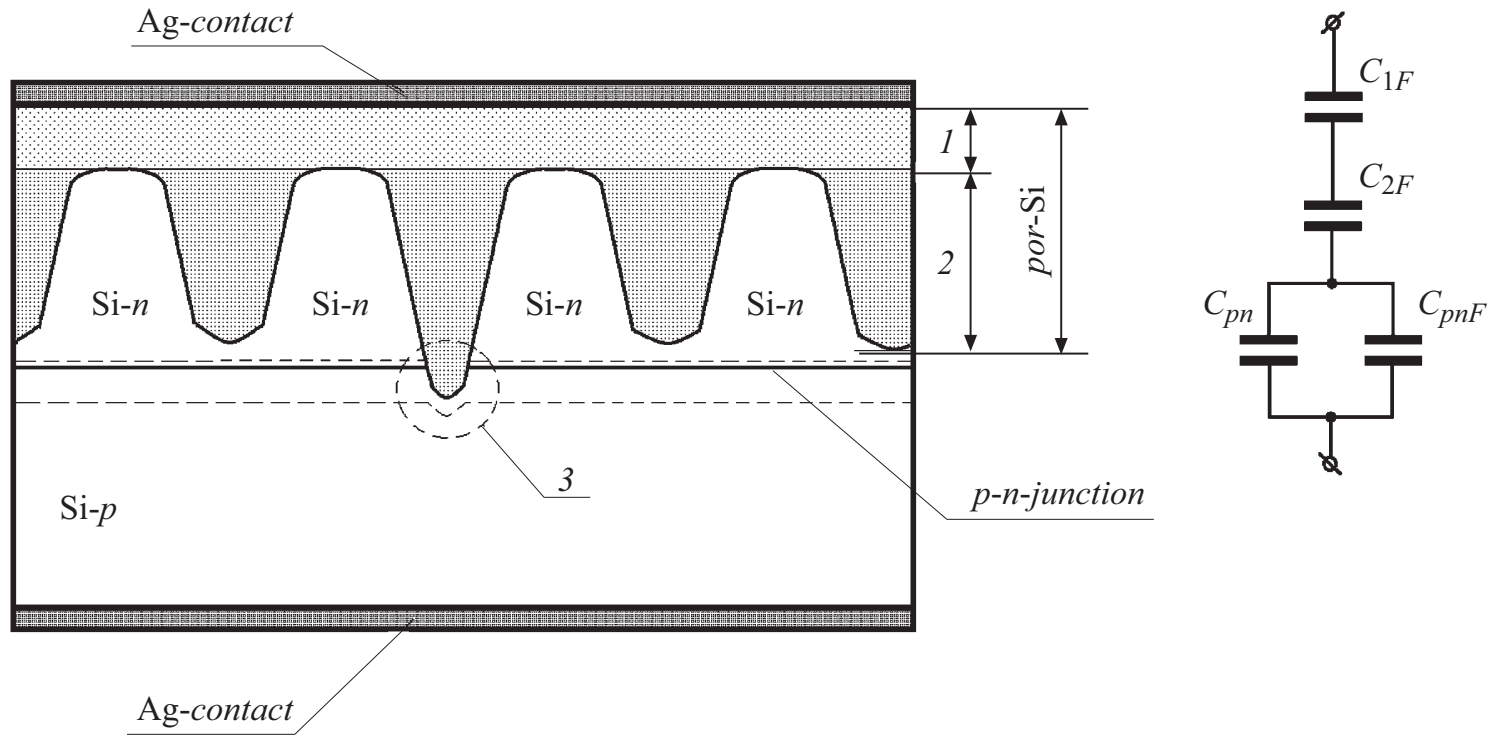

Рис. 5. Модель строения слоев исследуемой полупроводниковой структуры и емкостная эквивалентная схема замещения (на вставке): 1 - приповерхностный слой por-Si, содержащий наиболее мелкие кристаллиты, 2 - внутренний слой роr-Si, 3 прокол $p-n$-перехода.

В [5] это объяснялось возникновением локальных проколов $p-n$-перехода нижней границей формирующейся пленки por-Si. Таким образом, исследуемая полупроводниковая структура может содержать отдельные проколы $p-n$-перехода (область 3 на рис. 5), приводящие к возникновению дефектов с глубокими энергетическими уровнями.

Особенности ВФХ исследуемой полупроводниковой структуры могут быть объяснены с помощью емкостной эквивалентной схемы замещения, показанной на вставке на рис. 5. Параллельное соединение емкостей $C_{p n}$ и $C_{p n F}$ определяет общую емкость $p-n$-перехода исследуемой полупроводниковой структуры. Величина $C_{p n}-$ составляющая емкости $p-n$-перехода без учета влияния дефектов с глубокими энергетическими уровнями, не зависящая от частоты измерительного сигнала. При обратном смещении величина $C_{p n}$ определяется барьерной емкостью $p-n$-перехода. Составляющая емкости $C_{p n F}$ определяется влиянием дефектов с глубокими энергетическими уровнями в области пространственного заряда $p-n$-перехода, возникающими вследствие формирования пленки por-Si. Данная составляющая емкости зависит от частоты измерительного сигнала.

Последовательно соединенные емкости $C_{1 F}$ и $C_{2 F}$ определяют общую емкость поверхностной МДП-структуры, возникающей в результате формирования пленки por-Si (вставка на рис. 5). Величина $C_{1 F}$ является емкостью приповерхностного слоя por-Si (область 1 на рис. 5) и зависит от частоты измерительного сигнала, что обусловлено энергетическими уровнями ловушек на поверхности кремниевых кристаллитов. Исследование спектров фотолюминесценции показало, что с ростом длительности электрохимического травления толщина данного слоя por-Si возрастает, следовательно, вели- чина $C_{1 F}$ при фиксированной частоте измерительного сигнала должна уменьшаться. Емкость $C_{2 F}$ определяется внутренним слоем por-Si, содержащим более крупные кремниевые кристаллиты (область 2 на рис. 5). Величина $C_{2 F}$ зависит от частоты, так как учитывает влияние состояний на поверхности кристаллитов. Так как увеличение длительности электрохимического травления приводит к росту толщины пленки por-Si, емкость $C_{2 F}$ при этом уменьшается.

В соответствии с емкостной эквивалентной схемой замещения (вставка на рис. 5) значение полной емкости исследуемой полупроводниковой структуры описывается выражением

$$
C=\left[C_{1 F}^{-1}+C_{2 F}^{-1}+\left(C_{p n}+C_{p n F}\right)^{-1}\right]^{-1} .
$$

Наблюдаемые в настоящей работе особенности частотной зависимости ВФХ исследуемой полупроводниковой структуры можно объяснить на основе предложенной модели строения слоев (рис. 5) и формулы (1) следующим образом.

При высокой частоте измерительного сигнала (1 MHz) общая емкость поверхностной МДП-структуры, определяемая последовательным соединением $C_{1 F}$ и $C_{2 F}$, оказывается меньше, чем общая емкость $p-n$-перехода $\left(C_{p n}+C_{p n F}\right) . \quad$ Вклад составляющей $C_{p n F}$ при этом не проявляется, так как ловушки c глубокими энергетическими уровнями, имеющие длительные времена релаксации, не успевают следовать за измерительным сигналом. Вследствие указанной причины значения $C_{1 F}$ и $C_{2 F}$ при высокой частоте также имеют минимальные значения. Таким образом, на основании формулы (1) при высокой частоте измерительного сигнала наибольший вклад в общую 
емкость вносит поверхностная МДП-структура $\left(C_{1 F}\right.$ и $\left.C_{2 F}\right)$. Рассмотренная ситуация характерна для образцов № 2-4.

При снижении частоты происходит рост составляющих емкости поверхностной МДП-структуры $C_{1 F}$ и $C_{2 F}$ за счет того, что ловушки на поверхности кремниевых кристаллитов успевают следовать за измерительным сигналом. Одновременно увеличивается общая емкость $p-n$-перехода $\left(C_{p n}+C_{p n F}\right)$ за счет роста составляющей $C_{p n F}$, которая определяется влиянием дефектов с глубокими энергетическими уровнями. Однако при небольших длительностях процесса электрохимического травления образуется меньше дефектов с глубокими уровнями в области пространственного заряда $p-n$ перехода, поэтому вклад составляющей $C_{p n F}$ относительно небольшой. Так как в этом случае общая емкость поверхностной МДП-структуры превышает емкость $p-n$-перехода, то, согласно (1), результирующая ВФХ, главным образом, определяется влиянием барьерной емкости $p-n$-перехода. Эта ситуация справедлива для образцов № 2 и № 3.

Исследование спектров фотолюминесценции образцов № 2-4 показало, что рост длительности процесса электрохимического травления приводит к увеличению толщины слоя 1 пленки por-Si (рис. 5). При этом также увеличивается толщина слоя 2 пленки por-Si (рис. 5). В результате значения емкостей $C_{1 F}$ и $C_{2 F}$ при фиксированной частоте измерительного сигнала снижаются. Также с увеличением длительности электрохимического травления происходит рост концентрации дефектов с глубокими уровнями в области пространственного заряда $p-n$-перехода вследствие увеличения числа проколов нижним фронтом растущей пленки por-Si. Для образца № 4 внутренняя граница пленки por-Si лежит ниже плоскости $p-n$-перехода. При этом $p-n$-переход значительно поврежден. В этом случае, согласно формуле (1), наибольший вклад в ВФХ вносит емкость поверхностной МДП-структуры.

Снижение общей емкости полупроводниковой структуры при фиксированной частоте измерительного сигнала с ростом длительности процесса электрохимического травления для образцов № 2-4 (рис. 1-3) может быть связано с увеличением толщины слоев 1 и 2 пленки por$\mathrm{Si}$ (рис. 5), приводящим к снижению емкостей $C_{1 F}$ и $C_{2 F}$.

При прямом смещении поведение ВФХ исследуемой полупроводниковой структуры определяется, главным образом, влиянием ловушек с глубокими энергетическими уровнями на поверхности кремниевых кристаллитов в пленке por-Si.

\section{Заключение}

В результате проведенных исследований объяснены особенности частотной зависимости ВФХ полупроводниковой структуры, содержащей антиотражающую пленку por-Si над $p-n$-переходом. Установлено, что вид ВФХ в диапазоне частот измерительного сигнала $1 \mathrm{kHz}-1 \mathrm{MHz}$ определяется конкуренцией емкости $p$-n-перехода и поверхностной МДП-структуры, возникающей в пленке por-Si вследствие неоднородности ее строения. Значительное влияние на ВФХ оказывают ловушки с глубокими уровнями на поверхности кремниевых кристаллитов и дефекты в области пространственного заряда $p-n$-перехода, возникающие в ходе формирования пленки por-Si. Полученные результаты могут быть полезны при разработке фотоэлектрических преобразователей солнечной энергии с антиотражающей пленкой por-Si и оптических датчиков.

Представленные результаты получены в рамках выполнения государственного задания Министерства образования и науки РФ № 3.9506.2017/8.9 в Рязанском государственном университете им. С.А. Есенина.

\section{Список литературы}

[1] Handbook of Porous Silicon / Ed. by L. Canham. Springer International Publishing, 2014. $1017 \mathrm{p}$.

[2] Zheng J.P., Jiao K.L., Shen W.P. // Appl. Phys. Lett. 1992. Vol. 61. P. 459-461.

[3] Трегулов В.В. // ЖТФ. 2014. Т. 84. Вып. 9. С. 153-154.

[4] Трегулов В.В., Степанов В.А., Литвинов В.Г., Ермачихин А.В. // ЖТФ. 2016. Т. 86. Вып. 11. С. 91-94.

[5] Трегулов В.В., Литвинов В.Г., Ермачихин А.В. // Письма в ЖТФ. 2017. Т. 43. Вып. 21. С. 3-9.

[6] Венгер Е.Ф., Горбач Т.Я., Кириллова С.И., Примаченко В.Е., Чернобай В.А. // ФТП. 2002. Т. 36. Вып. 3. С. 349 354.

[7] Горячев Д.Н., Беляков Л.В., Сресели О.М. // ФТП. 2004. Т. 38. Вып. 6. С. 739-744.

[8] Мельник Н.Н., Трегулов В.В. // КСФ. 2015. Т. 42. Вып. 3. C. 19-24.

[9] Горячев Д.Н., Беляков Л.В., Сресели О.М. // ФТП. 2003. Т. 37. Вып. 4. С. 494-498.

[10] Евтух А.А., Каганович Э.Б., Манойлов Э.Г., Семененко Н.A. // ФТП. 2006. Т. 40. Вып. 2. С. 180-184. 